\title{
Da lei ao direito: processos, políticas e instrumentos na construção do direito à cidade
}

\author{
De la ley al derecho: maletines, instrumentos y políticas en la \\ construcción del derecho a la ciudad
}

\section{The right of law: cases, instruments and polices in the construction of the right to the city}

\author{
Marcos Aurélio Pelegrina \\ marcospelegrina@gmail \\ Universidade Estadual de Santa Catarina \\ Eduardo Donizeti Girotto \\ egirotto@usp.br \\ Universidade de São Paulo
}

Resumo: Um breve olhar sobre as legislações relacionadas às questões urbanas na atualidade nos levam a crer que houve um significativo avanço no que diz respeito à efetivação do direito à cidade. Porém, o que temos verificado em práticas recorrentes em diversos municípios brasileiros é a reafirmação dos princípios de produção e reprodução do espaço urbano sob a lógica da forma mercadoria. Em certa medida, tais ações se dão a partir da apropriação que determinados grupos sociais, principalmente aqueles vinculadores ao setor imobiliário, cada vez mais internacionalizado, realizam dos instrumentos técnicos e legais de organização da cidade. Tal apropriação é também resultado do desconhecimento de muitos destes instrumentos por grande parte da população, inclusive aquela que milita nos movimentos sociais urbanos. O cadastro territorial multifinalitário vem gradativamente sendo implementado na gestão territorial urbana de algumas cidades no País. A falta deste importante instrumento no processo de urbanização amplificam as contradições da produção dos processos urbanos. Neste sentido, o presente trabalho busca discutir de que forma o cadastro territorial multifinalitário em fase de implementação na cidade de Cascavel-PR, surge como um importante instrumento de fiscalização e produção do espaço e como o mesmo deve ser apropriado pelos movimentos de direito à cidade como uma forma de se contrapor ao discurso hegemônico da cidade submetida à lógica da mercadoria.

Palavras-chave: Cadastro territorial multifinalitário. Movimentos sociais. Sistema de informações territoriais.

Resumen: Una breve mirada a las leyes relacionadas con los temas urbanos hoy en día nos lleva a creer que había un progreso significativo en cuanto a la realización del derecho a la ciudad. Pero lo que hemos encontrado en la práctica en muchas provincias solicitantes es una reafirmación de los principios de la producción y reproducción del espacio urbano bajo la lógica de la forma mercancía. Hasta cierto punto, estas acciones se producen a partir de la apropiación que ciertos grupos sociales, especialmente los enlazadores a los bienes raíces, cada vez más internacionalizado, realice los 
instrumentos técnicos y la organización legal de la ciudad. Así que la propiedad es también el resultado de la ignorancia de muchos de estos instrumentos por parte de la población, incluida la que milita en movimientos sociales urbanos. En este sentido, el presente trabajo analiza como el cadastro territorial mutifinalitário llevando a cabo en la ciudad de serpiente de Cascavel-PR, emerge como una importante herramienta para la supervisión y organización del espacio y la forma en que debe ser apropiado por los movimientos correctos a la ciudad como una manera de contrarrestar el discurso hegemónico de la ciudad sujeto a la lógica de la mercancía.

Palabras clave: Catastro multi propositivo. Movimientos sociales. Sistema de informaciones territoriales.

\begin{abstract}
A brief look at the laws related to urban issues today lead us to believe that there was a significant advance in respect of ensuring the right to the city. However, what we have seen in recurrent practices in several Brazilian cities is a reaffirmation of the principles of production and reproduction of urban space under the logic of the commodity form. To some extent, such actions take place from the appropriation that certain social groups, especially those related to real estate, more and more internationalized, technical tools and carry out the legal organization of the city. So ownership is also the result of ignorance of many of these instruments for much of the population, including one that militates in urban social movements. This paper discusses how the territorial multipurpose cadastre being implemented in the city of Cascavel-PR, emerges as an important tool for the supervision and organization of space and how it should be appropriated by the right moves to town as a way to counter the hegemonic discourse of the city subject to the logic of the commodity.
\end{abstract}

Keywords: Multipurpose cadastre. Social movements. Land information system.

\title{
INTRODUÇÃO
}

O modo de produção capitalista pressupõe a forma cidade como um dos elementos de sua reprodução: esta, talvez, seja uma das teses centrais daqueles que analisam a cidade sob a lógica marxista. Desde o momento em que se funda na expropriação dos trabalhadores dos seus meios de produção (sendo o principal deles a terra), o modo de produção capitalista produz uma intensa onda de migrações campo-cidade. Tal processo pode ser verificado em diversos países, em diferentes momentos. Porém, além de produzir urbanização, o modo de produção capitalista submete esta nova forma de organização espacial às suas contradições intrínsecas. $\mathrm{O}$ que equivale, portanto, a afirmar que o urbano, no interior do modo de produção capitalista, reproduz as contradições deste tipo de sociabilidade.

No caso brasileiro, às contradições típicas do modo de produção capitalista somamse aquelas relacionadas ao nosso processo de colonização que, como sabemos, teve em seu caráter fundiário um dos seus principais elementos. A posse de terra no Brasil, desde o momento da colonização, esteve associada ao poder que, aos poucos, foi migrando do mero poder simbólico ao que hoje representa um importante poder econômico. As diferentes leis que regeram a terra no Brasil reafirmam este caráter relacional entre a 
posse da terra e o poder, como pode ser verificado na criação da lei de terras de 1850 . Neste sentido, a nossa herança colonial criou uma cultura em torno da terra não como direito de todos, mas propriedade ligada ao poder e à renda.

Tais elementos culturais, associados àqueles ligados à inserção do Brasil de forma mais intensa no modo de produção capitalista, resultaram em um processo de urbanização híbrido, que carrega em si, ao mesmo tempo, a marca do urbano e do rural. Ao mesmo tempo em que se industrializa de forma mais efetiva a partir da segunda metade do século XX, o Brasil constrói cidades sem romper, de fato, com o poder representado pela posse da terra verificado no rural. Se tais evidências não parecem claras em grandes metrópoles como São Paulo, Rio de Janeiro e Belo Horizonte, são bem visíveis em cidades pequenas e médias. Se no passado, a posse da terra estava vinculada ao poder simbólico, hoje se transmuta em poder econômico e em capacidade de definir os processos de produção do urbano.

\section{DA CIDADE COMO OBRA À CIDADE COMO PRODUTO}

Um dos principais autores que discute as questões urbanas na contemporaneidade é Henry Lefebvre. Suas contribuições são fundamentais, uma vez que permitem compreender as mudanças de sentido e significado que ocorrem na cidade e no urbano após o desenvolvimento de modo de produção capitalista com a industrialização. Como aponta o autor, a cidade, como uma forma material e histórica da apropriação do meio pelas diferentes sociedades humanas, precede o surgimento do capitalismo. Em cada momento histórico e em cada lugar a cidade, assume funções e características específicas, desde a cidade política, no caso da Polis Ateniense, até os burgos essencialmente comerciais na transição da Idade Média para a Moderna. Apesar das diferentes funções e sentidos, o que aproxima tais experiências de organização urbana é o fato de que constituem essencialmente práticas urbanas assentadas no valor de uso da cidade. Para o autor, tais cidades:

São centros de vida social e política onde se acumulam não apenas as riquezas como também os conhecimentos, as técnicas e as obras (obras de arte, monumentos). A própria cidade é uma obra e esta característica contrasta com a orientação irreversível na direção do dinheiro, na direção do comércio, na direção das trocas, na direção dos produtos. Com efeito, a obra é o valor de uso e o produto é o valor de troca (LEFEBVRE, 1969, p.10)

Tal valor de uso, pautado na construção da cidade enquanto obra, é profundamente alterado a partir do processo de industrialização que se espalha de forma desigual e combinada para todo o mundo a partir da Europa e, mais especificamente, da Inglaterra. Com este processo, que busca totalizar as diferentes formas de relações sociais que acontecem nas cidades, institui-se a lógica da mercadoria, na qual tudo passa a ter sentido no ato de compra e venda de um determinado produto. A cidade, sob a industrialização, não foge a este destino. Seu sentido e as práticas que ali ocorrem tendem a se resumir 
à lógica das relações entre coisas, entre mercadorias intercambiáveis. Configura-se, portanto, a lógica da cidade como produto, como uma mercadoria igual a qualquer outra, que deve ser produzida no interior da lógica do mercado. Há o advento, neste sentido, da hegemonia da cidade como valor de troca, construída não mais como bem comum ou como um patrimônio cultural da humanidade.

Neste processo, a indústria produz cidade como valor de troca em escala ampliada. Todos os investimentos feitos na produção do urbano se direcionam a partir dos interesses da reprodução ampliada do capital. Os investimentos em infraestrutura, saneamento, mobilidade urbana tem como principal meta garantir as condições para que a lógica do consumo, da reprodução da sociedade produtora de mercadoria possa ocorrer de forma cada vez mais eficaz. A cidade deixa de ser uma experiência humana para se torna lugar da relação entre coisas, entre mercadorias inseridas nesta lógica perversa de reprodução. O direito à cidade, assentado essencialmente do direito do valor de uso da cidade, da obra que ela representa, desaparece no interior da lógica do consumo. Como aponta Lefebvre (1969, p. 12, "a cidade e a realidade urbana dependem do valor de uso. O valor de troca e a generalização da mercadoria pela industrialização tendem a destruir, ao subordiná-las a si, a cidade e a realidade urbana". A cidade, na lógica do valor de troca, não é para todos. Podem dela desfrutar aqueles que apresentam determinadas condições econômicas, que podem, portanto, consumi-la. A todos os outros, que não apresentam as condições financeiras suficientes para este único tipo de prática aceitável na cidade mercadoria, resta a segregação, o fechamento em torno de uma parte da cidade, aquela que lhe é permitida e que se resume, muitas vezes, ao mero habitat. Esta talvez seja a transformação mais profunda que a generalização da mercadoria a partir da industrialização traz para o debate acerca do direito à cidade. Segundo Lefebvre, na cidade como valor de troca, autonomiza-se uma determinada função, qual seja, a de morar e a separar-se da cidade, criando a ideia perversa do sinônimo de morar e habitar. Se analisarmos os diferentes planos de habitação colocados em prática no Brasil, desde o BNH até o Programa Minha Casa, Minha Vida, o que temos é o aprofundamento desta lógica de identificação do direito à cidade com o acesso à casa própria. A localização da maioria dos conjuntos habitacionais para a população de baixa renda encontra-se nas áreas mais distantes da cidade, inclusive naquelas sem nenhuma infraestrutura urbana. Enquanto isso, as áreas melhor localizadas, próximas dos diferentes equipamentos públicos permanecem no domínio dos grandes grupos imobiliários. Tal processo resulta naquilo que o autor denomina de lugar de consumo e consumo do lugar, qual seja, "o núcleo urbano tornase assim produto de uma qualidade para estrangeiros, turistas, pessoas oriundas da periferia, suburbanos" $(1969$, p.17). A cidade como produto, portanto, torna-se objeto de desejo daquelas que dela estão segregado em suas habitações à margem do direito e da cidade.

É esta totalização da cidade pela lógica da mercadoria que, para Lefebvre, constitui o elemento central da crise da cidade e da problemática urbana. Porém, se no início do processo de industrialização era este que dominava o processo de urbanização, na 
atualidade, este, por sua vez, assume diversas implicações passando inclusive a definir as novas formas e estratégias de expansão industrial. Segundo Lefebvre:

A tese aqui apresentada é a de que a problemática urbana desloca e modifica profundamente a problemática originada do processo de industrialização. Enquanto a maioria dos teóricos e também dos práticos que procedem de maneira empírica consideram ainda a urbanização como consequência exterior e menor, quase acidental, do processo essencial, a industrialização, nós afirmamos o inverso. Nesse processo de duplo aspecto ocorre algo de muito importante, em termos clássicos: um salto qualitativo. $\mathrm{O}$ crescimento quantitativo da produção econômica produziu um efeito qualitativo que se traduz, ele próprio, por uma problemática nova: a problemática urbana. (LEFEBVRE, 2008, p. 80)

A problemática urbana surge, portanto, como elemento aglutinador no qual os múltiplos processos que dizem respeito à lógica de reprodução do capital se relacionam, às vezes ocultos, por outros já desvelados. Além disso, como aponta o autor, este salto qualitativo faz da problemática urbana um elemento central nas discussões sobre os limites da reprodução, seja da vida ou do capital. Torna-se, deste modo, tarefa essencial produzir uma análise crítica que seja capaz de articular as diversas contradições socioespacias da atualidade a partir da compreensão do que vêm a ser a problemática urbana e as diferentes formas-conteúdo que assume no cotidiano. Em nossa perspectiva, é preciso considerá-la a partir dos limites e possibilidades que traz à reprodução de toda sociedade, seja aquela ligada diretamente a lógica do capital, seja alguma outra que propõe o valor de uso para além da forma mercadoria.

No caso brasileiro, a problemática urbana assume formas específicas e que devem ser levadas em consideração. Segundo Lucio Kowarick, em seu livro “A espoliação urbana", os processos relacionados à expansão da urbanização estão diretamente relacionados a estratégias de barateamento da mão de obra e, consequentemente, a busca de maiores lucros advindos da exploração do trabalho pela indústria. Para o autor,

as periferias, como fórmula de reproduzir nas cidades a força de trabalho, é consequência direta do tipo de desenvolvimento econômico que se processou na sociedade brasileira nas últimas décadas. Possibilitou, de um lado, altas taxas de exploração do trabalho, e de outro, forjou formas espoliativas que se dão ao nível da própria condição urbana da existência a que foi submetida a classe trabalhadora. (KOWARICK, 1980, p. 41).

Se nos países capitalistas centrais, principalmente os da Europa ocidental, este processo se deu a partir de investimentos intensos feitos pelo estado em áreas como educação, saúde, moradia, o que resultou no chamado estado de bem-estar social, no caso brasileiro, o que houve foi um aumento da exploração do trabalho. Em muitos casos, não foi o estado o responsável pelos investimentos em moradia. Coube aos trabalhadores tal investimento, o que pode ser verificados em muitos casos de autoconstrução encontrados na cidade de São Paulo. Ou, quando o estado se responsabilizava com os investimentos em moradia como no caso do BNH (Banco Nacional de Habitação) e mais recentemente 
das COHABs (Companhia de Habitação) e CDHU (Companhia de Desenvolvimento Habitacional e Urbano), a aplicação dos recursos ficou restrita à construção de casas e apartamentos. Muito pouco é destinado à implementação das infraestruturas necessárias para que o direito à cidade efetivamente se realize.

Neste sentido, o acesso à moradia se realiza, portanto, como mero fragmento que espolia mais, pois transfere ao trabalhador os custos de sua própria reprodução, e ao empresário, os lucros desta espoliação. Como aponta Kowarick:

Na realidade, as necessidades sociais, numa situação em que as reivindicações e protestos coletivos estão bloqueados, são instrumentalizados em função das necessidades da acumulação. Assim os investimentos, nos quais é preponderante a participação estatal visam a lubrificação da engrenagem econômica e os problemas vividos pela população só se transformam em problemas públicos na medida em que são compartilhados pelas camadas dirigentes. (KOWARICK, 1980, p. 50).

Ao se reproduzir, portanto, o modo de produção capitalista reproduz sua desigualdade inerente e cria aquilo que, espacialmente, denominamos de periferias. De modo geral, as periferias podem ser definidas como áreas com pouca ou nenhuma infraestrutura urbana (água encanada, rede de esgotamento sanitário), falta de regularização fundiária, pouca presença do estado no que diz respeito aos investimentos necessários para que os direitos humanos sejam garantidos (escolas, hospitais, áreas de lazer). Porém, não se pode aplicar o termo excluídos para definir tais territórios da cidade. É exatamente por estarem incluídas na reprodução do modo de produção capitalista que tais áreas se formam e configuram. Suas morfologias não são resultantes da exclusão, mas do processo diretamente relacionado à dinâmica de expansão do modo de produção capitalista. Ao se reproduzir, incorporando novos territórios à sua lógica de reprodução, ao mesmo tempo em que não garante as mínimas condições de apropriação coletiva daquilo que produz, o modo de produção capitalista "empurra" uma grande parte da população para as áreas mais distantes das centralidades principais da cidade. São nestas áreas, que Haroldo de Gama Torres denomina de fronteira urbana ${ }^{1}$, que as novas periferias vão se formando, resultando assim em um processo constante de reprodução da desigualdade do espaço urbano.

Porém, a produção da desigualdade na periferia não está apenas na dificuldade de acesso aos bens materiais. Segundo Milton Santos,

Morar na periferia é se condenar duas vezes a pobreza. À pobreza gerada pelo modelo econômico, segmentador do mercado de trabalho e das classes sociais, superpõe-se a pobreza gerada pelo modelo territorial. Este, afinal, determina quem deve ser mais ou menos pobre somente por morar neste ou naquele lugar. Onde os bens sociais existem apenas na forma mercantil, reduz-se o numero dos que potencialmente the têm acesso, os quais se tornam ainda mais pobres por terem de pagar o que, em

1 Nesta perspectiva, a categoria fronteira urbana aponta para um tipo particular de periferia, com altíssima taxa de crescimento demográfico e precariedade no acesso a serviços públicos, particularmente saneamento (TORRES, HAROLDO DA GAMA,2004). 
condições democráticas normais, teriam de lhe ser entregues gratuitamente pelo poder público. (SANTOS, 1992, p.15).

Neste sentido, o processo de periferização do espaço urbano é também resultante de um modelo de urbanização pautado na lógica do consumidor que acaba por substituir a figura do cidadão. As formas mercantis de relações tornam-se dominantes, sendo que, aqueles despossuídos da mercadoria dinheiro, têm negado os usos da cidade.

Na cidade, sobretudo na grande, os cimentos se dissolvem e mínguam as solidariedades ancestrais. Ali onde o dinheiro se torna a medida de tudo, a economização da vida social impõe uma competitividade e um selvagismo crescentes (...) Em lugar do cidadão surge o consumidor insatisfeito e, por isso, votado a permanecer consumidor. Sua dependência em relação aos novos objetos limita sua vocação para obter uma individualidade e reduz possibilidades dos encontros interpessoais diretos e enriquecedores, porque simbólicos em sua própria origem. (SANTOS, 1992, p.16-17)

Neste sentido, o aprofundamento dos processos relacionados à produção desigual do espaço urbano resulta em alargamento da crise da cidade. Segundo Damiani, vivemos o momento no qual o processo de urbanização, resultante da relação intrínseca com a expansão do capitalismo industrial e financeiro, tornou-se crítico. Para a autora, a urbanização crítica "é a impossibilidade do urbano para todos, a não ser que se transformem radicalmente as bases da produção e da reprodução sociais" (DAMIANI, 2004, p. 30). Tal impossibilidade está também no fato de que no momento atual do desenvolvimento capitalista, estamos vivendo a negatividade absoluta do trabalho, o trabalho como negação de toda possibilidade de realização da vida. Cada vez mais, o trabalho como atividade criativa humana é substituído pelo trabalho sem significado, pelo trabalho abstrato que tem o fim em si mesmo (KURZ, 2004). Marcada pela dupla contradição (da urbanização crítica e do trabalho abstrato enquanto negado e negação), a cidade como valor de troca revela as contradições e os limites de toda a reprodução social no interior do modo de produção capitalista.

Diante deste quadro, há que construir processos de mobilização popular que busquem uma efetiva apropriação daquilo que está garantindo a lei com o intuito de produzir políticas públicas que engendrem, efetivamente, o direito à cidade. Para tanto, faz-se necessário que desenvolvamos processos e instrumentos legais e técnicos que podem ser utilizados no fomento de mobilizações com o intuito de ampliar o debate acerca do direito à cidade, rompendo com hegemonia dos grupos dominantes que se acham no direito quase "natural" de definir e organizar o espaço urbano. Para que isso ocorra, no entanto, é fundamental questionarmos o papel da universidade e do conhecimento (neste caso específico, da geografia) na construção, sistematização e divulgação de tais instrumentos. Enquanto lugar da construção de um conhecimento essencialmente público, a universidade precisa assumir a sua responsabilidade neste processo, buscando dialogar com os diferentes sujeitos do direito à cidade, seja através de assessoria técnica, seja por meio da construção de instrumentos para a efetiva gestão democrática do território. 
Entre tais instrumentos, destacamos neste trabalho as experiências desenvolvidas com o Cadastro Territorial Multifinalitário, no município de Cascavel, como importante ferramenta na construção de um processo de gestão democrática do território. A Federação Internacional de Geômetras - FIG - (acrônimo francês de Federação Internacional de Agrimensores) é uma entidade internacional que reúne associações nacionais profissionais e instituições de pesquisa da área da ciência da medição. Dentre as várias comissões que compõem a FIG, destaca-se a comissão 7 (sete), que trata especificamente do Cadastro e da Gestão Territorial. Esta comissão produz inúmeros documentos e declarações sobre o tema, além de publicações dirigidas em seus congressos e conferências.

No que se refere ao termo cadastro, define-se como "um sistema de informações territoriais (SIT) atualizadas e baseadas em parcelas, que contém um registro de interesses sobre a terra" (FIG, 1996). Ainda segundo a FIG, o cadastro territorial multifinalitário deve ter como base o cadastro, com descrição geométrica das parcelas, em conjunto com outros registros que descrevem a natureza dos interesses da parcela, tais como direitos, restrições e responsabilidades, bem como as condições desta propriedade ou o controle destes interesses. O cadastro territorial multifinalitário pode ser estabelecido para finalidades fiscais (p. ex., avaliação e tributação), legais (p. ex., transferências e certidões), administrativas (p. ex., planejamento e controle do uso da terra), bem como disponibilizar informações para o desenvolvimento sustentável e a proteção ambiental, tendo como base o cadastro territorial multifinalitário.

O cadastro está presente nas estruturas administrativas dos estados, independentemente do seu modo de produção ou regime político. O conceito de território, considerado na perspectiva do cadastro, é aquele onde o governo exerce sua autoridade com objetivo de racionalizar sua completa utilização. Dessa forma, ele não é apenas a superfície terrestre, mas compreende também o subsolo, o espaço aéreo e o mar territorial (LOCH; ERBA, 2007).

As Organizações das Nações Unidas (ONU) definem como gestão territorial o processo de determinar e disseminar informações sobre situação legal dos imóveis, uso e valor da terra e seus recursos associados (FIG, 1996), informações essas provenientes do cadastro territorial multifinalitário. $\mathrm{O}$ estabelecimento de um cadastro territorial multifinalitário tem por objetivo atender as necessidades de natureza legal, fiscal e administrativa que envolvam a ocupação e a forma de domínio do território. A necessidade legal ou jurídica consiste na garantia da propriedade; a necessidade fiscal consiste na cobrança de impostos sobre o uso do solo; a necessidade administrativa compreende as demais atividades relacionadas ao planejamento e à gestão do território (BRANDÃO; SANTOS FILHO, 2008).

Um SIT, base do cadastro territorial multifinalitário, deve ser composto por intermédio da delimitação geométrica das parcelas do território, também denominado de cadastro físico. Quanto aos aspectos econômicos da ocupação do solo, são registradas no cadastro denominado de econômico, no qual estão descritos os valores venais dos imóveis, utilizados para tributação imobiliária. Por fim, o cadastro jurídico, onde são registrados os aspectos legais da ocupação do território. 
O país possui, basicamente, dois tipos de cadastro: um relativo à área rural e outro à área urbana. O cadastro dos imóveis rurais é de competência do Instituto de Colonização de Reforma Agrária (INCRA), que obteve um grande avanço ao se consolidar com a promulgação da Lei $n^{\circ} 10.267 / 2001$, que trata de alterações na Lei dos Registros Públicos. Tal lei modifica a sistemática relacionada à identificação dos imóveis rurais, permitindo o desenvolvimento do Cadastro Nacional de Imóveis Rurais (CNIR) e obrigando, gradativamente, o georrefereciamento dos imóveis de acordo com as normas técnicas. Esta ação permitirá, no futuro, uma integração entre o registro público e o cadastro do INCRA, ou seja, nas áreas rurais integração entre o cadastro físico e o jurídico.

Com a criação do Ministério das Cidades, sentiu-se a necessidade de elaborar políticas públicas para implantar um cadastro territorial multifinalitário urbano, como ferramenta fundamental para a gestão urbana dos municípios. $O$ foco do novo cadastro não se restringe à cobrança de impostos, mas apresenta um sistema amplo com informações para auxiliar nos processos de tomada de decisão e, consequentemente, de democratização da gestão territorial. Neste sentido, o ministério criou um grupo de estudo para elaborar as diretrizes nacionais do cadastro territorial. Além dessa ação, também vêm sendo promovidos seminários, oficinas e publicações de materiais com esta temática. Essa nova visão fica explícita na citação do manual do cadastro publicado pelo ministério, (BRASIL, 2010):

A terra pertence a todos, pelo menos um mínimo de sua porção espacial tem que ser socializado, todos os que aqui habitam temporariamente têm direito a ter acesso ela, têm direito à terra com serviços mínimos. Só existe propriedade, juridicamente sustentável, quando a mesma estiver cumprindo a sua função social amplamente considerada, o que é assegurado pela existência de um cadastro amplo e atualizado, com o qual se possibilita ações eficientes do Estado no que tange à ordenação de seu território.

\section{O MUNICÍPIO DE CASCAVEL-PR}

Localizada no oeste do Paraná, Cascavel é considerada a cidade polo regional. Emancipada em 1952, passou por um intenso processo de crescimento demográfico e rápida urbanização nas últimas décadas. Localiza-se na região Oeste do estado do Paraná, sul do

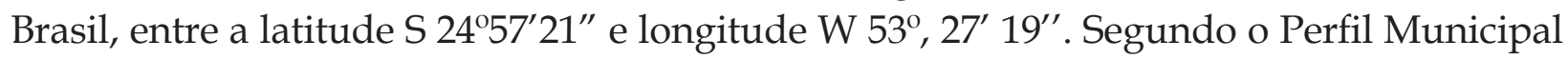
(PMC, 2004), o município de Cascavel integra a Mesorregião Geográfica número 06, com posição geográfica privilegiada em relação aos países do MERCOSUL (Mercado Comum do Cone Sul) por situar-se no principal entroncamento rodoviário. A economia é baseada na área da agropecuária e serviços, provavelmente uma futura metrópole da região oeste do Paraná.O município atinge a altitude máxima de 780 metros acima do nível do mar na área urbana, possuindo uma área total de $2.112,85 \mathrm{Km}^{2}$ (Figura 1). 
Figura 1 - Localização da área de estudo.

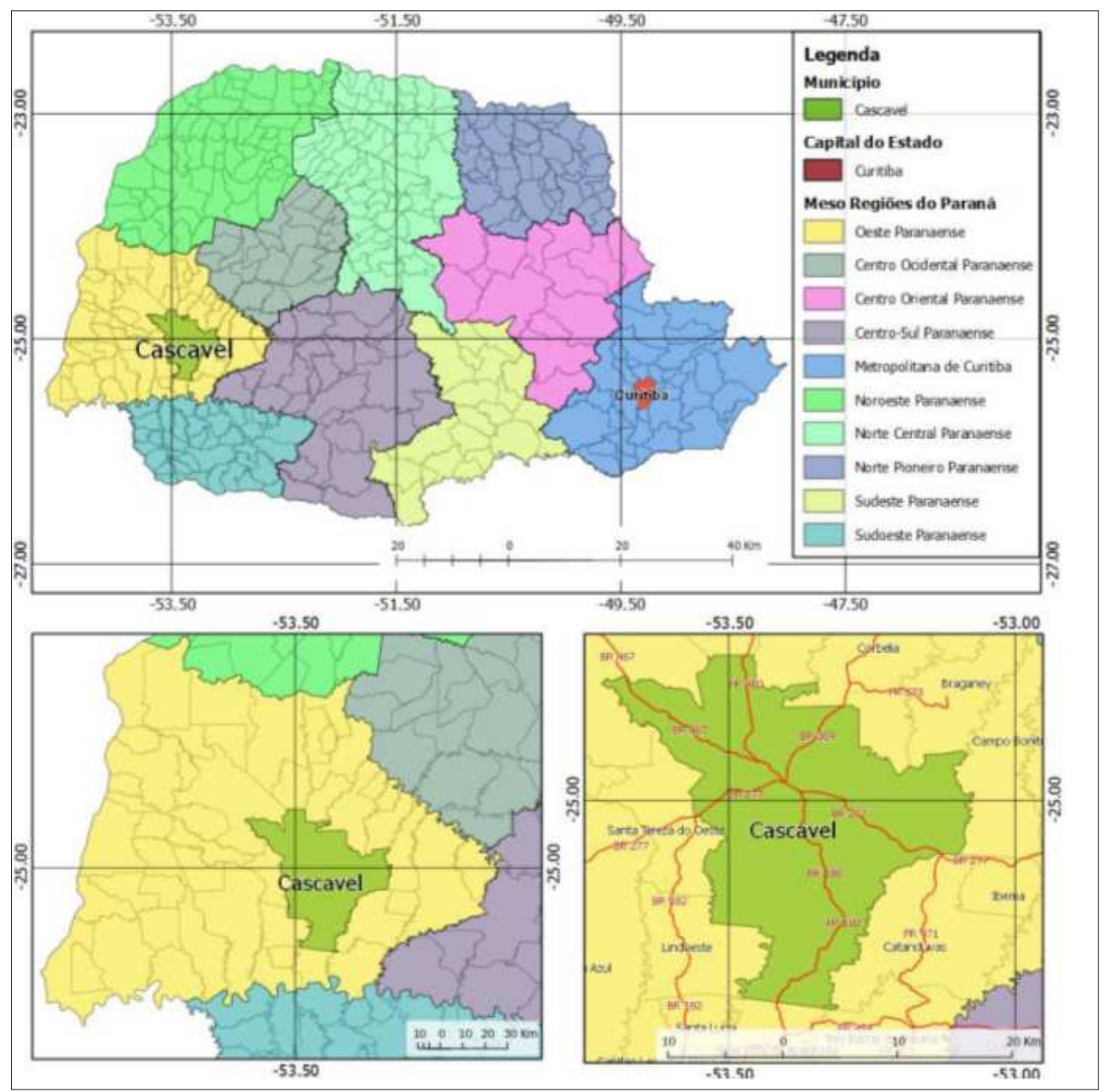

Fonte: IBGE Censo 2010. Org.: Valmorbida (2012)

Segundo o IBGE, no ano de 1960, a população total de Cascavel era de 39.598 habitantes. Já em 1970, o número total da polução era de 89.921. Em 1980, atingiu a casa dos 163.459 habitantes e, no ano de 1991 população já era de 192.990 habitantes. No censo populacional de 2000, a população total era de 245.369 e no último, em 2010, a população chegou 286.172 habitantes, (Gráfico 1). Houve um crescimento populacional da década de 1960 para os dias atuais maior do que 600\%, sendo que na década de 1980, a população urbana superou a população rural e, desde então, a distância só se tem ampliado. No ano de 2010, a cidade de Cascavel atingiu um grau de urbanização de 94,4 \%. 
Gráfico 1 - Evolução da população total do município de Cascavel-PR

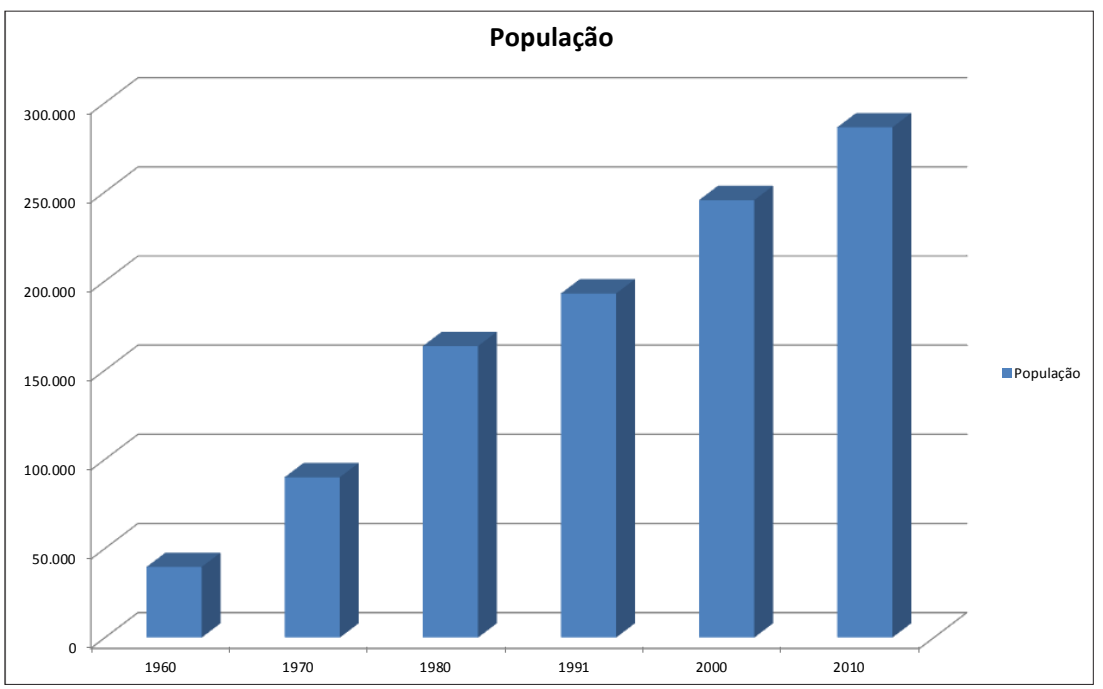

Fonte: IBGE. Org.: O autor.

Considerando a hierarquia definida por estudo do IBGE (2000), os estudos de Moura (2004 apud MALDANER et al., 2007), organizam centros medidos pelo desempenho de funções urbanas para o Paraná. No ano 1990, Curitiba era destaque como nível "máximo" de centralidade no conjunto de cidades paranaenses. Por isso, Curitiba é considerada o principal polo de irradiação de uma ampla gama de serviços que atendem a um amplo conjunto de municípios. Em segundo plano, apresentavam-se as cidades de Londrina e Maringá, com níveis "muito fortes" de centralidade, seguidas por Ponta Grossa e Cascavel, com níveis "fortes" de centralidade.

Ao estudar densidade urbana de Cascavel-PR, Valmorbida (2012) concluiu que classe de alta densidade urbana obteve o maior crescimento no sentido sul e ao leste da cidade. A classificação de média densidade urbana apresentou crescimento principalmente ao sul, leste e oeste da área urbana. E a classe de baixa densidade urbana apresentou crescimento da área urbana em todas as direções. Os principais eixos de expansão urbana foram os locais próximos à BR 277 e à PR 467. Já a área identificada como baixa densidade urbana é verificada no crescimento das áreas urbanas sobre a área rural. Existe uma tendência de verticalização nas áreas centrais identificada como área de alta densidade urbana (Figura 2). 
Figura 2 - Comparação temporal da densidade urbana da cidade de Cascavel-PR
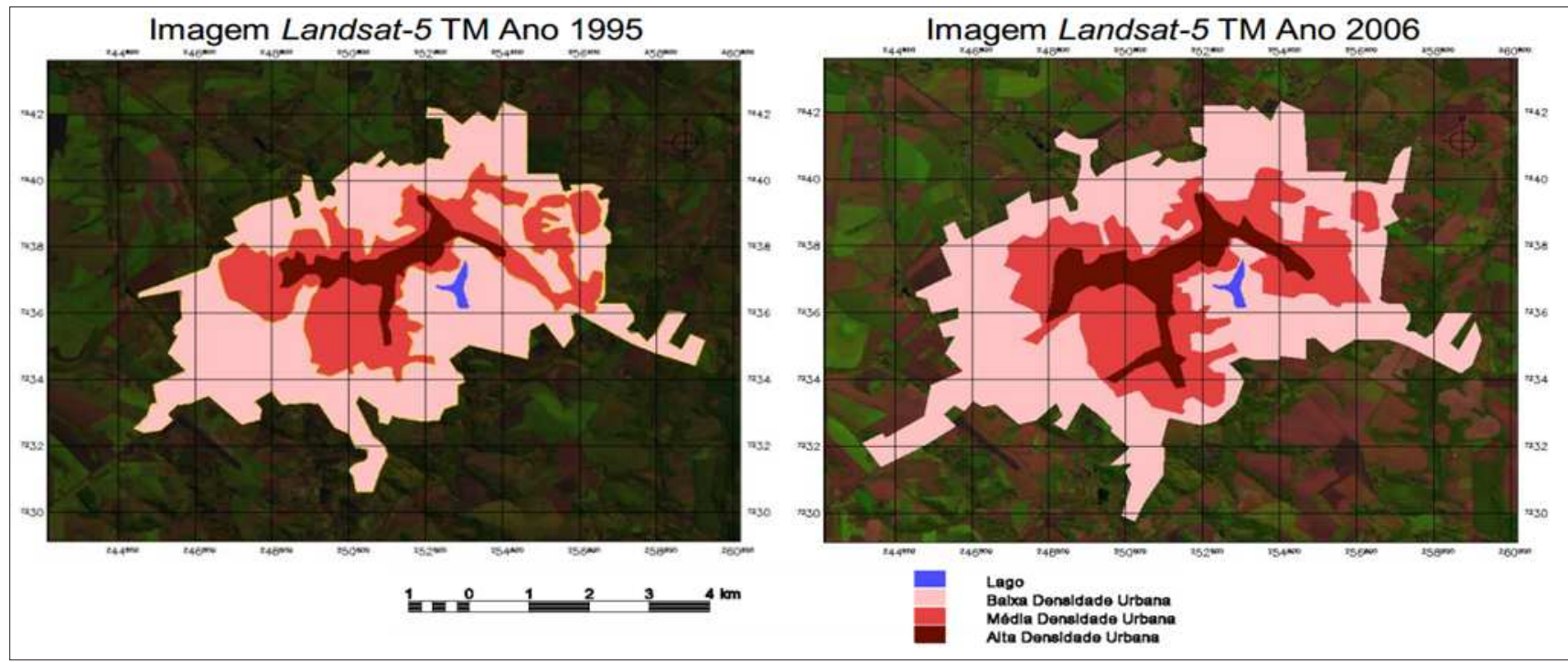

Org.: Valmorbida (2012).

Toda esta dinâmica da produção do espaço urbano em Cascavel traz importantes problemáticas no que diz respeito à construção do direito à cidade. Para que isso se realize, são necessários mecanismos efetivos de fiscalização que possibilitem aos diferentes segmentos da sociedade civil compreender a participação da produção do espaço e da gestão da cidade. Neste sentido, a construção do Geoportal de Cascavel, pautada nas discussões referentes ao Cadastro Territorial Multifinalitário, surge como uma tentativa de se constituir enquanto ferramenta de acesso a informação acerca dos diferentes processos e agentes vinculados a produção do espaço urbano no município.

Na Figura 03, observa-se o SIT (Sistema de Informações Territoriais), da cidade de Cascavel-PR, onde o geoportal está disponível para consulta da população desde março de 2012, no seguinte endereço eletrônico: <http:/ / geoportal.cascavel.pr.gov.br/geoportal/>.Esse serviço de internet, comum em alguns países, é denominado de "Mashup". Esse conceito refere-se à disponibilização de um serviço WEB que utiliza mais de uma fonte de dados para criar um novo serviço, no caso o Google Maps. Esse tipo de tecnologia voltada ao usuário tem por finalidade promover uma transparência na publicação de informações territoriais. No portal, verificam-se informações cadastrais dos imóveis como: metragens, benfeitorias e situação jurídicas (número de matrícula e do cartório) e restrições de uso. 
Figura 3: SIT do Município de Cascavel-PR

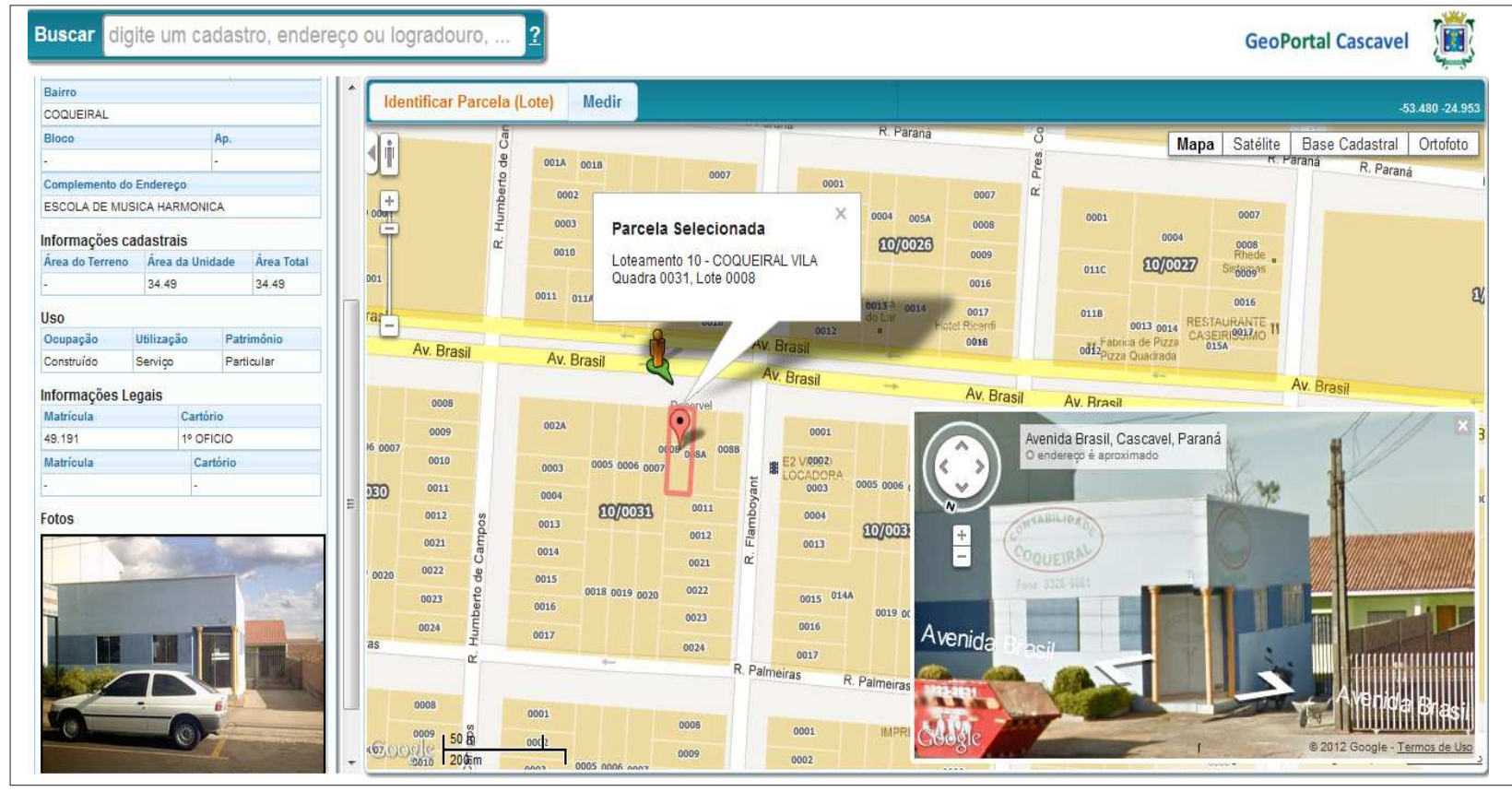

Fonte: http:/ / geoportal.cascavel.pr.gov.br

A legislação urbana referente ao uso e ocupação do território é dividida entre o código de obras e edificações, que visa normatizar toda e qualquer construção, reforma e ampliação de edifícios efetuada a qualquer título no território do município. E a lei de zoneamento e uso do solo, que visa disciplinar vocação e finalidade de cada zona ou área do território urbano, objetivando o desenvolvimento harmônico da comunidade, assegurando sua qualidade de vida. Em uma gestão territorial democrática, é necessário desenvolver instrumentos técnicos e científicos, para permitir o acesso dessas informações para toda a sociedade.

Na Figura 4, observa-se no quadro (a) o mapa de zoneamento, que tem como função publicizar o planejamento urbano e principalmente as áreas de restrição de uso como as áreas de preservação permanente. No quadro (b), a parcela selecionada está contígua entre áreas do zoneamento sendo: a) ZE (Zona de Estruturação) que como funcionamento da atividade residencial; b) ZFAU-SUOC 1: Zona de Fragilidade Ambiental Urbana Subzona de Uso e Ocupação Controlados, são áreas que integram as áreas que margeiam as APP (área de preservação permanente ) e dos cursos d'água em geral e veredas e parte da bacia manancial do rio Cascavel; c) ZFAU-SP: Zona de Fragilidade Ambiental Urbana Subzona de Proteção, áreas de preservação ambiental de proibição de uso e ocupação. Além de apresentar a lei de zoneamento através de um mapa que permite confrontação com as parcelas territoriais, essa ferramenta de consulta de viabilidade apresenta também os parâmetros de ocupação dos lotes, devendo atender aos limites estabelecidos para cada zona.

Esses instrumentos de democratização da informação territorial urbana têm como finalidade expor todos os parâmetros urbanísticos, permitindo a fiscalização por parte 
da sociedade civil. O desafio da administração municipal é educar a população sobre a importância do plano diretor e seu zoneamento no ordenamento e gestão territorial e a efetiva fiscalização da sociedade.

Figura 4 - Mapa de zoneamento (a), Consulta de Viabilidade (b)

a)

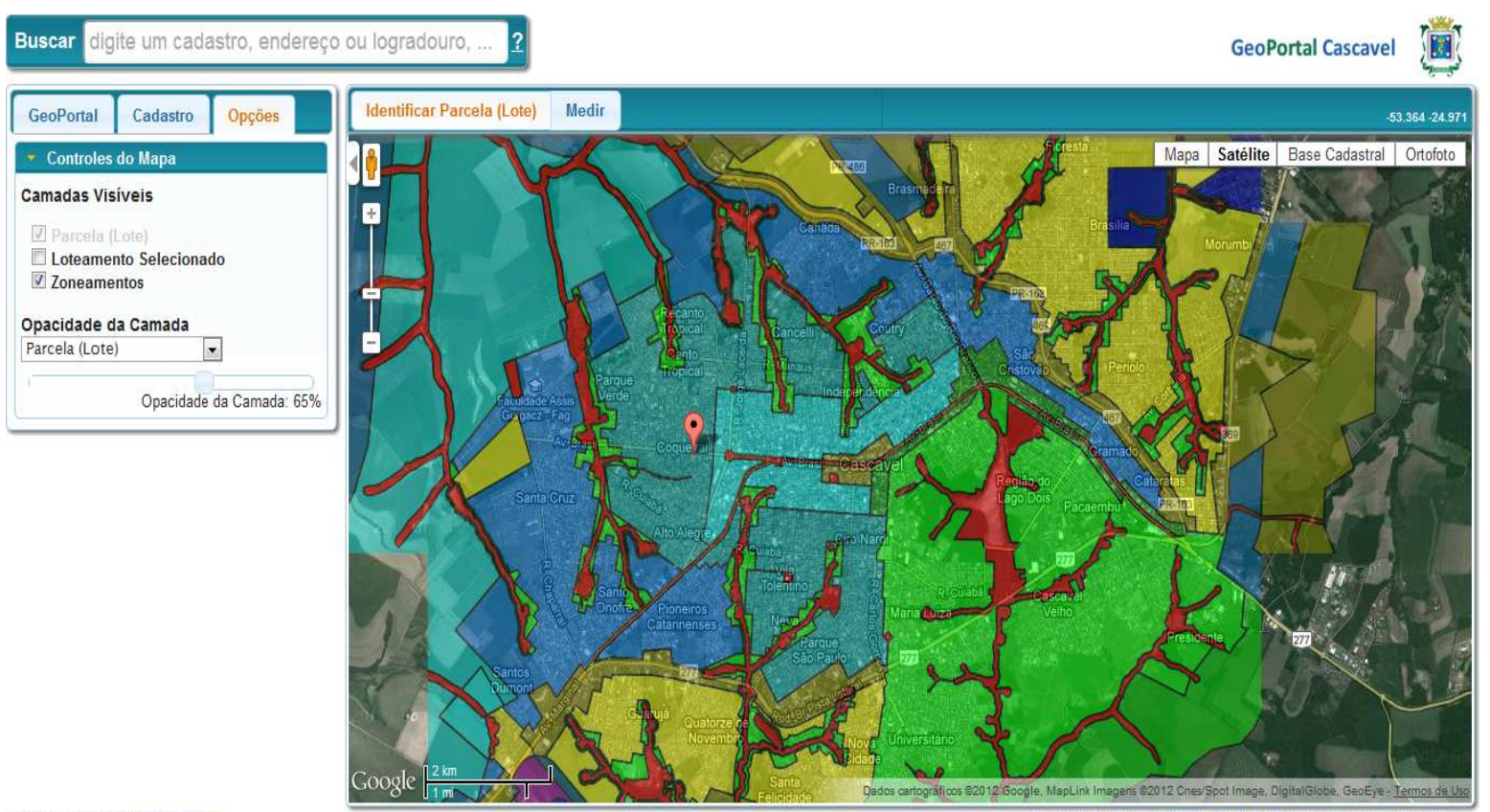

Projeto e Implementsạăo ITIS Teconologia

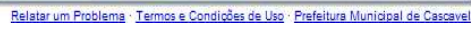

b)

Buscar digite um cadastro, endereço ou logradouro, ...

GeoPortal Cascavel
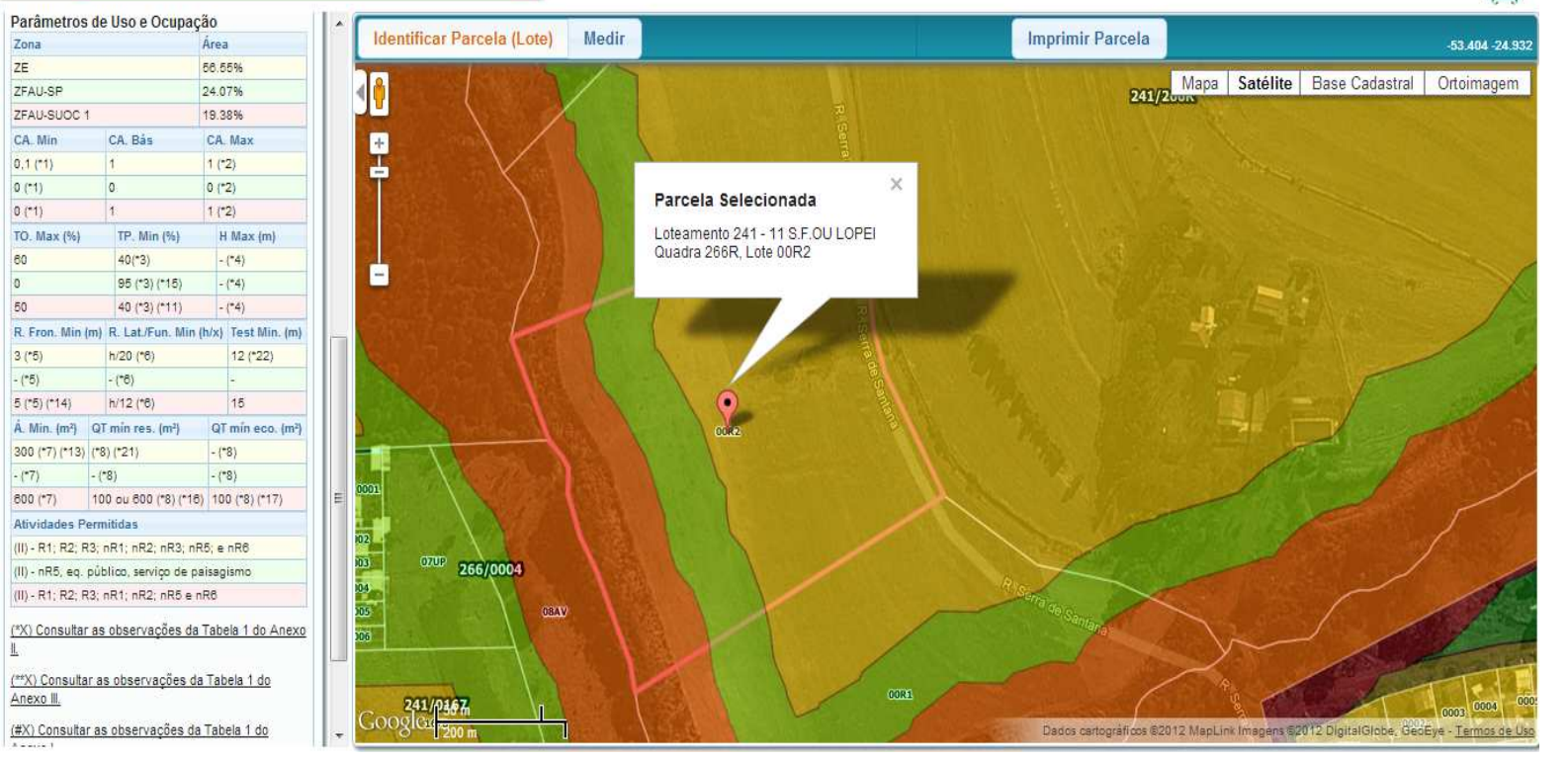

Fonte: http:/ / geoportal.cascavel.pr.gov.br 
Essas ferramentas presentes na implantação do Cadastro Territorial Multifinalitário, que está sendo implementado gradativamente na cidade de Cascavel, disponibiliza essa proposta de plano diretor desde a sua primeira publicação no início do ano de 2012. As discussões do novo plano diretor que ainda está tramitando na câmara de vereadores pode ser realizado utilizando-se dessas ferramentas disponíveis no geoportal enriquecendo o debate e permito acesso à informação territorial de toda a sociedade civil.

Além disso, o geoportal Cascavel permite ao cidadão realizar denúncias através da opção de relatar um problema. No futuro, está previstaa conexão das redes sociais ao sistema e dessa com a ouvidoria da prefeitura. A ideia desse serviço é o georreferenciamento das denúncias e demandas da sociedade e a publicidade das respostas da administração municipal.

Outro elemento, destacado no geoportal, diz respeito à fiscalização da construção de moradias, em parceria com o CREA-PR.A administração municipal aderiu ao programa Casa Fácil do CREA-PR. Esse programa disponibiliza profissionais do Conselho para execução de projetos de moradias populares. Essas ações visam impedir a construção de moradias clandestinas, evitando catástrofes futuras. Também, aumenta o poder de fiscalização da cidade. Na figura 05 , os imóveis destacados são aqueles fiscalizados pelo CREA-PR, sem alvará de construção. Ou seja, esse imóvel está irregular frente às normas vigentes da Prefeitura Municipal.

Figura 5 - SIT do Município de Cascavel-PR, imóveis sem alvará de construção

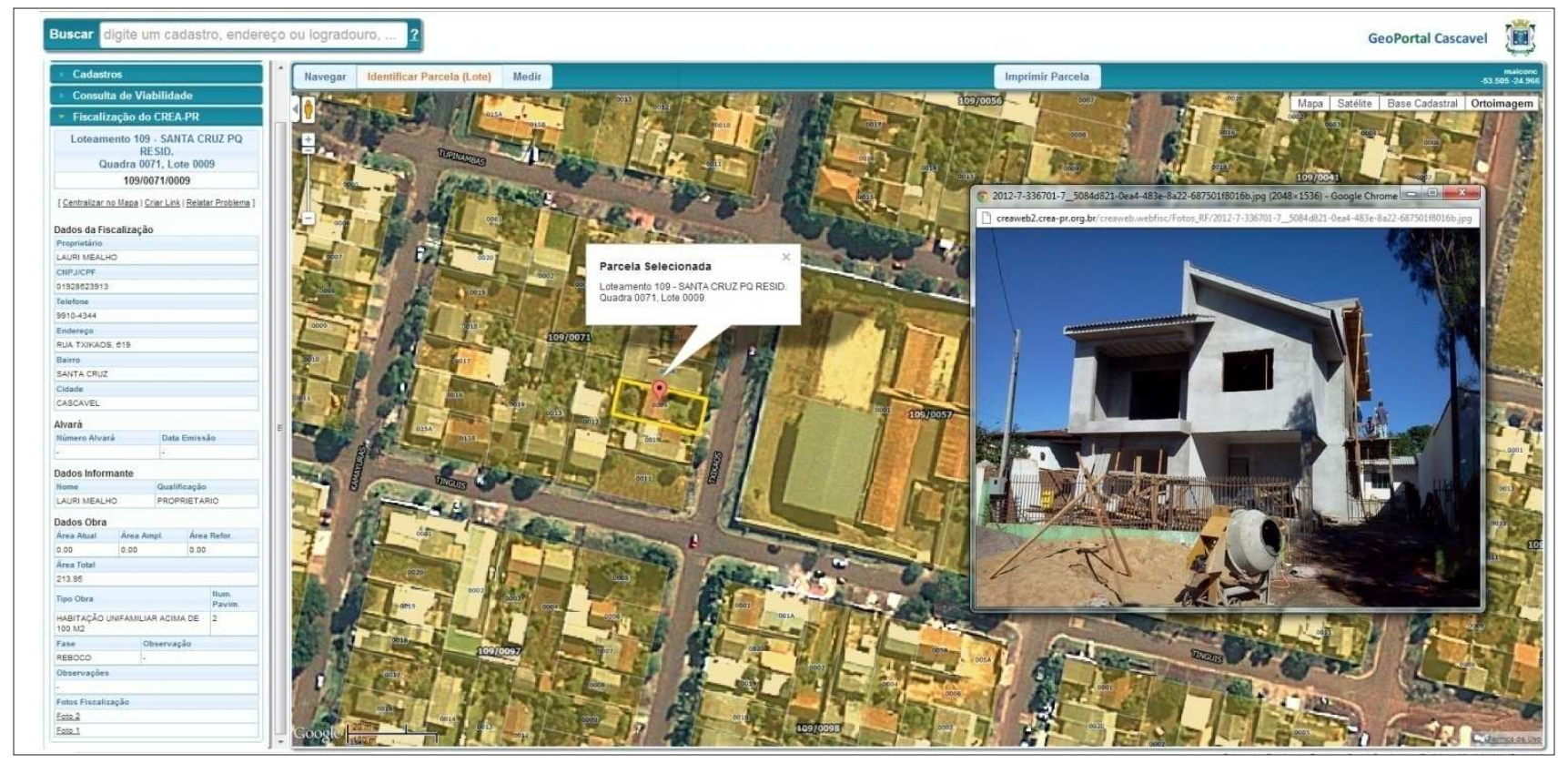

Fonte: Prefeitura Municipal de Cascavel - Secretaria de Planejamento e Desenvolvimento Urbano - Divisão do Sistema Único de Informações -Eng. Máicom Canal

Outro exemplo de uso do geoportal está na Figura 6. Nela se verifica que o lote selecionado no meio da área urbana da cidade, denominado no cadastro como chácara, é um exemplo de área reservada para especulação imobiliária, com atividade agrícola. 
Apesar de o uso ser de uma atividade rural, o imóvel é tributado através pelo imposto predial territorial urbano (IPTU). Essa contradição entre reserva de terras e o uso agrícola deve ser debatido com sociedade incluindo todos os autores para definir o melhor uso dessa área.

Figura 6 - Área de uso agrícola encrava no meio urbano na cidade de Cascavel-PR

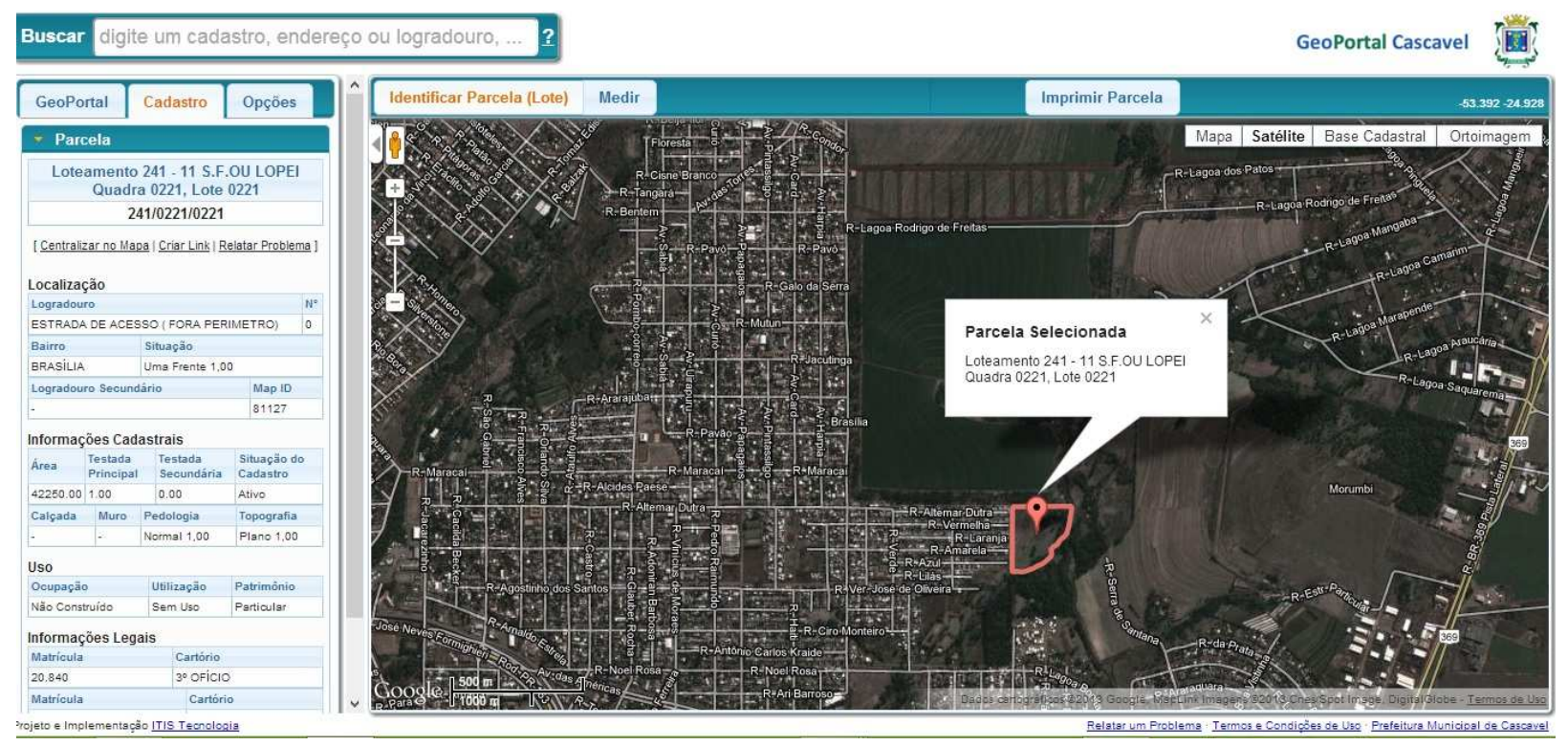

Fonte: http://geoportal.cascavel.pr.gov.br

Vale ressaltar que a utilização do Cadastro Territorial Multifinalitário e a construção de ferramentas de acesso à informação sobre a produção do espaço urbano deve vir acompanhado de uma série de outras ações, tanto de ordem infraestrutural, quanto no que se refere à formação dos sujeitos que irão lidar com estas informações. No caso de Cascavel, além de desenvolver o geoportal para o acesso das informações, existe no município uma rede de internet pública, permitindo o acesso de internet à população de baixa renda. Além disso, existem inciativas de formação de professores, principalmente vinculados à geografia, para que possam discutir em suas aulas estas informações, replicando-as entre os alunos.

\section{CONSIDERAÇÕES FINAIS: DA LEI AO DIREITO}

Como vimos, muitos são os desafios a serem enfrentado para a realização do direito à cidade. $\mathrm{O}$ cadastro territorial multifinalitário vem gradativamente sendo implementado na gestão territorial urbana de algumas cidades no país, sendo que a falta deste importante instrumento pode amplificar as contradições da produção do espaço urbano. Neste sentido, enquanto pesquisadores de importantes universidades públicas no sudoeste e do centro-oeste do Paraná, acreditamos que podemos contribuir, seja por meio de formações ou desenvolvimento de instrumental técnico, para que aquilo que está 
posto na lei possa, efetivamente, se realizar.

Em nosso caso, ao lidarmos com a realidade cada vez mais complexa de Cascavel-PR, buscamos desenvolver experiências de gestão democrática da cidade com o intuito de que, se bem sucedidas, elas possam se tornar exemplos para outros municípios. As problemáticas urbanas, que se reproduzem em Cascavel, apesar de complexas, não são impossíveis de serem resolvidas. Para tanto, não basta apenas o discurso técnico, que tem marcado a produção do espaço urbano nas últimas décadas. A técnica só tem sentido se acompanhada de um profundo componente ético. E, em nossa perspectiva, tal componente está na construção de políticas públicas que pensem a cidade como direito de todos, como obra e valor de uso e não como mercadoria.

Sendo assim, os Planos Diretores não podem ser alterados conforme os interesses daqueles que lucram com tais mudanças, fazendo com que a população pobre seja obrigada a procurar imóveis em áreas mais distantes em decorrências dos preços elevados de aluguéis, enquanto condomínios de classe média alta são construídos nos topos de morro da cidade, acompanhando obras específicas que têm como principal objetivo ampliar a especulação imobiliária.

Neste sentido, apesar dos avanços legais representadas pela promulgação de leis bastante progressistas como o Estatuto da Cidade e a instituição da obrigatoriedade dos Planos Diretores e da participação popular em sua elaboração, o que temos visto é um processo de manutenção das estratégias de reprodução do espaço urbano conforme os interesses dos principais grupos dominantes. Em nossa perspectiva, tal processo é uma consequência do distanciamento da população em relação ao entendimento de tais legislações, que acabam sendo apropriadas pelos técnicos, fundando assim a autoridade do chamado discurso competente, apontado por Marilena Chauí. Com isso, uma legislação progressista, quando não apropriada pelos diferentes sujeitos da cidade, se torna alvo de interesses particulares, como poder ser claramente verificado em várias cidades brasileiras.

Tal utopia deve ser construída a partir de outro projeto de sociedade. Daí a nossa defesa da necessidade de se pensar e construir o direito à cidade. Se vivemos, por enquanto, a hegemonia do modelo neoliberal, autoritário, homogeneizador, o que propomos com o direito à cidade é a busca por uma unidade que possa abarcar, sem restringir, as diferentes experiências particulares, situadas e contextualizadas. Neste novo senso comum, os valores construídos de forma coletiva só podem ganhar sentido a partir de diferentes práticas. $\mathrm{O}$ direito à cidade não se realiza pelo discurso. Está nas lutas dos homens e mulheres espalhados em múltiplos territórios. O que os une são os valores do bem comum, da solidariedade, da cooperação. E são tais valores, em nossa perspectiva, que devem nortear as políticas públicas e o conhecimento que construímos. 


\section{REFERÊNCIAS}

ALVES, S. F. Direito De Acesso À Informação Pública: Legislação Urbana na Internet. Assentamentos Humanos: Revista da Faculdade de Engenharia, Arquitetura e Tecnologia da Universidade de Marília, v.5, n. 1, p. 17-24, out. 2003.

BRANDÃO, A.; SANTOS FILHO, A. V. Sistema de Cadastro Territorial Georreferenciado em Áreas Urbanas. Revista VeraCidade, v. 3, n. 3, s/p., maio de 2008.

BRASIL. Manual de Apoio - CTM: Diretrizes para a criação, instituição e atualização do cadastro territorial Multifinalitário nos municípios brasileiros. Brasília: Ministério das Cidades, 2010. (Org.: Eglaisa Micheline Pontes Cunha e Diego Alfonso Erba).

DAMIANI, A. L. Urbanização Crítica e Situação Geográfica a partir da metrópole de São Paulo. CARLOS, A. F. A.; OLIVEIRA, A. U. de (Orgs.) Geografias de São Paulo: Representação e Crise da Metrópole. São Paulo: Contexto, 2004, p. 15-35.

KOWARICK, L. A Espoliação Urbana. São Paulo: Paz e Terra, 1980.

KURZ, R. Com todo o vapor ao colapso. Juiz de Fora: Editora UFJF, 2004.

LEFEBVRE, H. Espaço e política. Belo Horizonte: UFMG, 2008.

A Revolução Urbana. Belo Horizonte: UFMG, 2004.

O direito à cidade. São Paulo: Documentos, 1969.

LOCH, C.; Erba, A. Cadastro Técnico Multifinalitário: Rural e Urbano. Cambridge, MA: Lincoln Institute of Policy, 2007.

MALDANER, I. S.; LIMA, J. F.; GRECO, S. C. B. A Estrutura Urbana no Oeste do Paraná: a influência da cidade de Cascavel no seu entorno. Ra'e ga - O Espaço Geográfico em Análise, v. 14, p. 7-18, 2007.

SANTOS, M. O espaço do cidadão. 2. ed. São Paulo: Nobel, 1993.

UNITED NATIONS/FIG. Bogor Declaration on Cadastral Reform. Symposium on Cadastre and Land Management, 64th. FIG (Federação Internacional de Geômetras). Bogor Indonésia, 1996. Disponível em: <http:/ / www.fig.net/commission7/ reports/bogor/BogorDeclaration.html>. Acesso em: 10 maio 2010.

VALMORBIDA, L. Densidade urbana e populacional e seus efeitos multitemporais na cidade de Cascavel/PR. 2012. Dissertação (Mestrado- Programa de Pós-Graduação em Geomática) - Universidade Federal de Santa Maria, Centro de Ciências Rurais, Santa Maria-RS.

Recebido em 13/09/2012

Aceito para publicação em 30/10/2012 